\title{
OFD - DESDOBRAMENTO DA FUNÇÃO QUALIDADE - ESTRUTURANDO A SATISFAÇÃO DO CLIENTE
}

Fábio de Souza Abreu Mestrando na EAESP/FGV e palestrante do Gvpec - Programa de Educação Continuada da EAESP/FGV.

RESUMO: Muito tem se falado sobre a importância para a empresa de focar o cliente e atender às suas necessidades, porém pouco se fez para mostrar como chegar a isso de forma eficiente. Empresas de porte mundial têm usado o Desdobramento da Função Qualidade - QFD (do inglês Quality Function Deployment) para atender aos seus clientes, com sucesso em vendas e market share. A aplicação do QFD traz ainda outros benefícios, como redução no tempo e custo de desenvolvimento de produtos, maior eficiência nos processos de benchmarking, trabalho em equipes, desenvolvimento simultâneo e melhora na comunicação interdepartamental. $O$ artigo apresenta uma explicação conceitual do funcionamento do QFD e comentários sobre a implantação do método na empresa.

ABSTRACT: Business specialists have given full attention to the customers' needs and delighting them for the business success. On the other hand, very few practical and tested methodologies have been presented to the Brazilian managers. World-class companies have been applying regularly the Quality Function Deployment - QFD to satisfy successfully the customers' needs and improving sales and market share at same time. Besides, other benefits come up applying QFD method like reducing costs and the lead time spent on product development, more effective benchmarking processes, efficient team work, real concurrent development and better interfunctional communication. This paper ends up giving a conceptual explanation how QFD works and comments about its implementation.

PALAVRAS-CHAVE: QFD - Desdobramento da Função Qualidade, "voz do cliente", desenvolvimento de produtos e serviços, trabalho em equipe, vantagem competitiva, processos, comunicação interfuncional.

KEY WOROS: QFD - Quality Function Deployment, "customer voice", product and service development, team work, competitive advantage, processes, interfunctional communication. 
1. AKAO, Y. (ed.). Quality Function Deployment - integrating customer requirement into product design. (Prefácio). Cambridge (Mass.) Productivity Press, 1990

2. Vide comentário de Akashi Fukuhara (diretor da Central Japan Ouality Contro Association - CJQCA), in: EUREKA, W. E., RYAN, N. E. OFD - Perspectivas gerenciais do Desdobramento da Função Qualidade. Rio de Janeiro: Quality Mark Editora, 1993, p. 56

3. Em 1983, quando o prof. Akao apresentou um estudo a respeito na conferência em Chicago, várias empresas japonesas já utilizavam o QFD em diversos setores (destacadamente: mecânico, eletromecânico, eletrônico, químico, farmacêutico, alimentar, têxtil de construções). MERLI, G. Tota manufacturing management. Cambridge (Mass.): Productity Press, 1990, p. 222.

4. Uma comparação dos custos de start up e pré-producão da Toyota Auto Body. entre 1977 antes da utilização do QFD em conjunto com outras téenicas modernas de produção e 1984 quando 0 modelo estava adequadamente implantado aponto redução de mais de $60 \%$. Também o tempo de desenvolvimento de um novo modelo foi reduzido de cinco para três anos. HAUSER, J. R., CLAUSING, D. The hous of quality. Harvard Business Review, 66 , n. 3, p. $63-73$, may-jun. 1988 Também na questão da melhoria contínua - OFD teve papel fundamental na Toyota; por exemplo, ao orientar a reducão do custo de garantia a níveis significantes em utilização conjunta com o método Taguchi. EUREKA. W. E., RYAN, N. E. Op.

5. HAUSER, J. R. How puritan-Bennett used the house of quality Sloan Management Review, v. 34, n. 3. p. 61 70 , spring 1993.

6. Desde então, empresas como Digita Equipment, Hewlet-Packard, AT\&T, ITT, Ford e GM, entre outras, têm utilizado o QFD. A Ford 0 utiliza em mais de 50 aplicações. Atualmente os japoneses estão utilizando também em serviços como bancos (melhorias nos caixas eletrônicos), escolas de natação, lojas de varejos e no layout de apartamentos. HAUSER, J. R., CLAUSING, D. Op. cit..
Os executivos brasileiros não precisam de mais conselhos, relatos de experiências e alertas sobre o risco de dar pouca atenção aos seus clientes. Eles precisam, isto sim, de métodos práticos, eficazes e que lhe indiquem, passo a passo, como satisfazer seu cliente. É exatamente desta necessidade que pretendemos tratar aqui.

Embora as empresas brasileiras mais modernas já tenham percebido a importância da correta compreensão das necessidades e desejos do cliente, a grande maioria desconhece a ferramenta sobre a qual iremos fazer uma introdução e seus benefícios. Vários artigos e livros foram publicados no Brasil sobre o Desdobramento da Função Qualidade QFD (do inglês Quality Function Deployment), mas as empresas

Muito fem se
falado sobre a
importância para
a empresa de
focar o cliente e
afender às suas
necessidades,
porém pouco se
fez para mostrar
como chegar a
isso de forma
eficiente.

dade, ou simplesmente QFD. Foi sistematizada por meio de matrizes em meados da década de setenta, nos estaleiros de Kobe, do grupo Mitsubishi Heavy Industries, o qual publicou uma brochura em 1978 em que os principais aspectos e idéias do QFD foram estruturados. ${ }^{3}$

Os empresários norte-americanos, impressionados com a objetividade e os resultados obtidos pela Toyota ${ }^{4}$ com o QFD, iniciaram em 1986, com a Xerox e a Ford, ${ }^{5}$ a história de um sólido sucesso na aplicação e adaptação à realidade das empresas ocidentais. O seu desenvolvimento tem sido notável, ${ }^{6}$ e seus conceitos foram introduzidos em cada aspecto do desenvolvimento de produtos, processos e serviços, trazendo resultados significativos: redução pela metade dos problemas encontrados nos estágios iniciais brasileiras ainda não aquilataram sua verdadei- do desenvolvimento de produtos, redução do temra importância como instrumento de po de desenvolvimento total do produto à metaalavancagem de vantagens competitivas e par- de (em alguns casos chegando a um terço), ao ticipação de mercado.

\section{O MÉTODO QFD - SEU HISTÓRICO E DESENVOLVIMENTO NO OCIDENTE}

$\mathrm{Na}$ década de 80 , as conquistas das empresas japonesas, tanto em tecnologia e qualidade como em fatias significativas de mercados por todo o mundo, inclusive o norteamericano, impressionaram as empresas ocidentais. Os empresários americanos e os estudiosos da administração voltaram-se à compreensão das técnicas gerenciais que apoiavam as empresas japonesas na obtenção de sua espetacular performance. Uma das empresas mais estudadas foi a Toyota, que estava entre as primeiras a lograr importantes resultados competitivos no mercado norte-americano. Seus produtos, de qualidade insuperável, eram também amplamente aceitos pelo mercado mundial.

Em 1983, numa conferência em Chicago, quase uma centena de empresários aguardava ansiosamente para ouvir o Prof. Yoji Akao ${ }^{1}$ sobre uma nova ferramenta à qual se atribuía a orientação do processo de qualidade dentro da Toyota. ${ }^{2}$ Antes conhecida como Hin Shitsu (atributos, funções), Ki No (função), Ten Kai (desdobramento, difusão), passou a ser chamada de Desdobramento da Função Quali- mesmo tempo que as vendas e a satisfação do cliente aumentaram. Um exemplo genérico do impacto do QFD nos custos de desenvolvimento de produtos é mostrado nos gráficos 1 e 2 .

Quando implementado corretamente, oQFD passa a ser parte importante da competência da empresa em entender e atender o cliente com qualidade superior $e$, assim, superar os concorrentes. Poucas ferramentas gerenciais desenvolvidas no Japão tiveram tanto sucesso no Ocidente como o QFD, o que talvez explique a pouca divulgação dos resultados obtidos pelas empresas que o utilizam. Afinal, por que elas o divulgariam, ou mesmo a metodologia que faz parte de sua competência central, já que são fonte de suas vantagens competitivas no mercado?

A atualidade do QFD se torna maior quando verificamos que hoje, após as grandes mudanças conquistadas pelas empresas ocidentais na última década em termos de qualidade e eficiência, elas se defrontam com mercados altamente competitivos, onde os diferenciais primários já foram superados pela maioria dos concorrentes (entrega, qualidade do produto, custos competitivo etc.). As fronteiras do diferencial competitivo estão na contínua busca da satisfação dos clientes, através da agregação de valor mediante serviços diferenciados, produção customizada, redução dos lead times da empresa e outras abordagens que conduzam a 


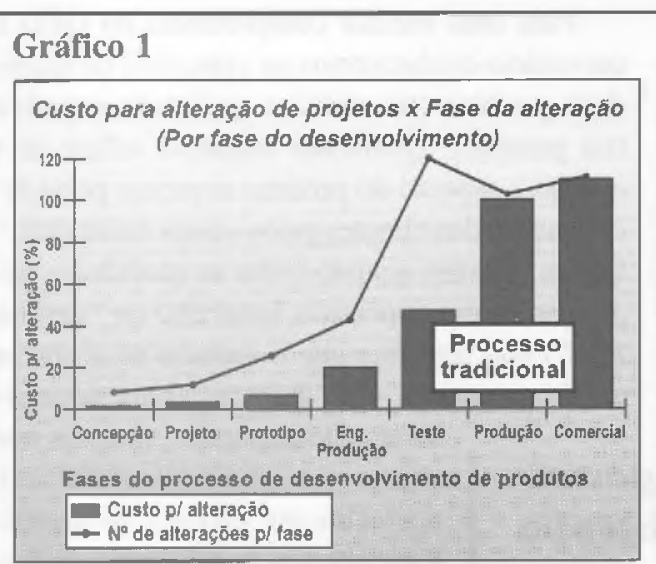

Ambos os gráficos trabalham com duas informações baseadas em dados genéricos, amplamente divulgados. Mostram uma tendência normalmente aceita por pesquisadores do processo de desenvolvimento de produtos. Apesar de algumas indústrias apresentarem escalabilidade dos custos mais acentuada (colunas) que outras, o importante é ver a quantidade de alterações que ocorrem na fase de desenvolvimento de um produto ou serviço (iinha) e o impacto gerado nos custos. Cabe

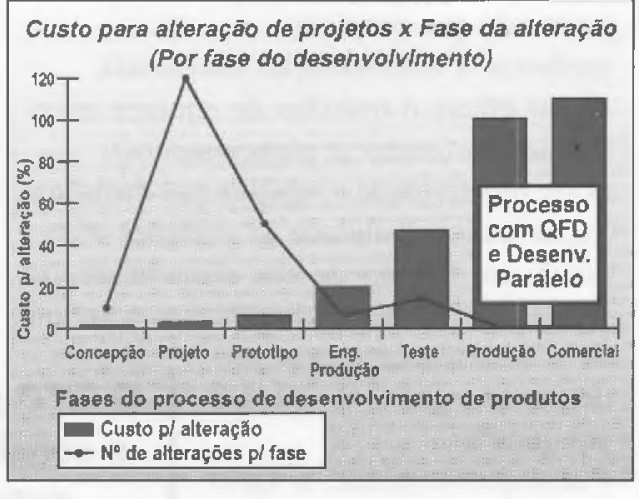

salientar que atualmente poucos pesquisadores consideram desenvolvimento simultâneo ou paralelo sem a utilização do QFD.

Os gráficos também explicam, em parte, a razão do menor tempo gasto no processo (outras razões estão no desenvolvimento paralelo e no trabalho em equipe), pois o tempo e os esforços despendidos para realizar uma alteração nas fases iniciais de um projeto são significativamente menores que nas complexas fases finais. empresa à frente dos concorrentes.

Para atingir novos requisitos competitivos ou escolher qual seguir, a empresu deve saber ouvir o que seus clientes dizem e rapidamente assimilar, sistematizar e transformar em produtos, serviços ou processos adequados os requisitos solicitados. É este o principal papel do QFD nas empresas ocidentais: ser um método de apoio ao desenvolvimento de produtos $^{7}$ e serviços para interpretar as necessidades e desejos dos clientes ("voz do

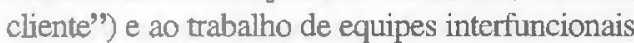
no desenvolvimento de produtos e serviços. Uma correta e efetiva tradução da "voz do cliente" $\mathrm{em}$ atributos técnicos de produtos ou serviços é obtida consistentemente através do QFD, aumentando as possibilidades de sucesso no mercado.

O QFD tem se revelado uma das principais ferramentas para as empresas reduzirem o tempo de desenvolvimento de novos produtos e aumentarem a satisfação de seus clientes, como já comentamos, porém não são desprezíveis seus resultados secundários, os quais são relatados por vários autores: ${ }^{8}$

- estrutura o processo de benchmarking ${ }^{9}$ so-

Poucas
ferramentas
gerenciais
desenvolvidas
no Japáo
iveram tanto
sucesso no
cidente como
o QFD.

bre produtos;

- funciona como uma linguagem e área de trabalho (framework) comum para que engenheiros e pessoal de mercado interajam produtivamente;

- traz maior integração das equipes de desenvolvimento;

- garante que as informações levantadas no início do processo de desenvolvimento junto ao cliente estejam presentes no produto lançado;

- prioriza os objetivos do processo de desenvolvimento de produtos.

A outra função básica do QFD - apoio ao trabalho de equipes interfuncionais (formadas por representantes de marketing, desenvolvimento e pesquisa, produção, pósvenda etc.) e ad hoc (a constituição da equipe muda à medida que o projeto evolui) - é obtida com procedimentos e atividades que melhoram em muito a comunicação, a estruturação do trabalho e a geração de idéias.

Com a maior experiência na aplicação e desenvolvimento de softwares específicos (os quais facilitaram em muito sua implementa-
7. Neste artigo, produto deve ser entendido de forma genérica isto é, como um serviço ou processo operaciona! que atenda a uma necessidade do cliente.

8. Ver os já citados HAUSER J.R. CLAUSING D.; MERLI, G.; EUREKA, W.E., RYAN, N. E

9. Para definirmos benchmarking utilizamos o conceito proposto em VAZIRI, H. K. Using competitive benchmarking to set goals. Quality Progress, act. 1992: "Benchmarking é o processo de comparar continuamente a performance da empresa $e$ de seus produtos, com base nos pontos aríticos requeridos pelo cliente, como melhor do setor en que atua (competidores diretos) ou em uma função especifica (empresas conhecidas por sua superioridade em sua performance em determinadas funçoes) para determinar o que deve ser melhorado" (p. 81) 
10. Uma das aplicações mais interessantes em que o QFD pode ser aplicado é no processo de desdobramento do Hoshin Plan-sistema de planejamento estratégico e sua ativação.

11.Esta definição foi retirada da obra já citada de Akao (p. 4), porém Merli, também já citado (p. 223), restringe o conceito de qualidade negativa aos problemas existentes dentro da empresa (atraso de fornecedores, defeitos nos produtos etc.). Optamos pela definição de Akao por ser mais abrangente adequada.

12. Uma outra forma de entender esse ponto é fazer com que o produto atenda os aspectos de produto potencial, conforme sugerido por Levitt. Estāo incluídas neste nível propriedades/ "surpresas" que, em função da sua qualidade, agradam e surpreendem 0 cliente (serviços adicionais). LEVITT, T. Marketing success through everything. Harvard Business Review, jan.-feb. 1980 p 83-94.

13. MERLI, G. Op cit, p. 223; HAUSER, J R., CLAUSING, D. Op cit, 63.

14. HAKES, C. Total Quality Management-The key to business improvement. London: Chapman \& Hall, 1991 . p. 117. ção), os executivos perceberam as possibilidades do QFD como um poderoso instrumento gerencial, que propicia:

- melhorar a comunicação horizontal;

- tornar eficaz o trabalho de equipes interfuncionais (como já mencionamos);

- obter objetividade e rapidez nas decisões;

- lograr maior qualidade às soluções oferecidas, em função de sua capacidade em agregar pontos de vistas diversos e permitir o detalhamento sem perder a visão global do assunto em questão.

Conseqüentemente, o QFD passou a ser utilizado para uma ampla gama de aplicações dentro das empresas, como as de orientação de programas para a qualidade, redesenho de processos, definição de programas de treinamento, aplicação dos critérios do Prêmio Malcolm Baldrige (no Brasil, Prêmio Nacional da Qualidade PNQ), implantação de planos estratégicos ${ }^{10}$ e de marketing. Ressalte-se, porém, que o QFD é antes de tudo uma metodologia flexível e desenvolvida na prática, razão pela qual deve ser adaptado às necessidades de cada aplicação.

\section{O MÉTODO QFD - UMA BREVE EXPLICAÇÃO}

Podemos considerar o QFD, na perspectiva da evolução do processo de desenvolvimento de produtos e serviços, como o primeiro método estruturado e sistematizado para orientar o processo e a execução das tarefas que envolvem desde a concepção até a colocação do produto no mercado, garantindo a transformação das necessidades e desejos dos clientes em produtos que efetivamente os satisfaçam.

Antes do aparecimento do QFD, a preocupação principal sobre o desenvolvimento de produtos era centrada na procura de um design organizacional facilitador $\mathrm{e}$ estimulador da criatividade e no aperfeiçoamento de ferramentas que garantissem a execução sequiencial de todas as tarefas envolvidas (Pert, por exemplo). $O$ desenvolvimento de produtos era visto como um esforço criativo, envolvendo um grande número de atividades não estruturadas, sujeito a uma certa probabilidade de sucesso comercial.
Para uma melhor compreensão do QFD é necessário conhecermos os conceitos de qualidade positiva (ou ativa) e qualidade negativa (ou passiva). Qualidade negativa refere-se a qualquer aspecto do produto expresso pelas reclamações dos clientes pelos canais existentes. ${ }^{11}$ Porém, mesmo quando todas as qualidades negativas forem superadas (conceito de "defeito zero") não significa que o sucesso da empresa esteja garantido, pois existem ainda necessidades não expressas, latentes nos clientes (ou qualidades positivas), normalmente difíceis de quantificar por serem colocadas de forma vaga e variável. Podemos saber quais os itens que devemos assegurar e melhorar os produtos existentes, porém para novos produtos temos que aprender $o$ $q u \hat{e}$ devemos assegurar. No QFD a atenção é direcionada para entender tanto as qualidades positivas como as já existentes e requeridas pelo cliente.

O QFD é um conjunto de matrizes cujo objetivo é focalizar e coordenar as habilidades dentro da organização para desenvolver produtos que não apenas eliminem as razões de reclamações dos clientes, mas também forneçam uma resposta ativa aos seus desejos e expectativas (inclusive aqueles que ainda não estão claros na sua mente ${ }^{12}$ ), gerando produtos que os clientes venham a desejar comprar e recomprar. ${ }^{13}$

$O$ QFD se estrutura para garantir que os desejos mais importantes do cliente sejam entendidos nos termos utilizados pelo próprio cliente. Tais desejos são ativados (deployed) em características técnicas mensuráveis do produto ou serviço (fase 1: planejamento); que por sua vez são ativadas nas especificações de componentes e partes (fase 2: partes); na adequação dos processos de produção (fase 3: processos) e, por fim, em padrões de procedimento no nível das operações (fase 4: operações) ${ }^{14}$ conforme podemos observar na figura 1.

Em outras palavras, QFD é um método para desenvolvimento de qualidade que visa à satisfação dos clientes mediante a tradução de suas necessidades mais importantes (por isso a representação da priorização através de um funil) em características técnicas, e estas em parâmetros a serem utilizados em todo o processo de produção e distribuição. 


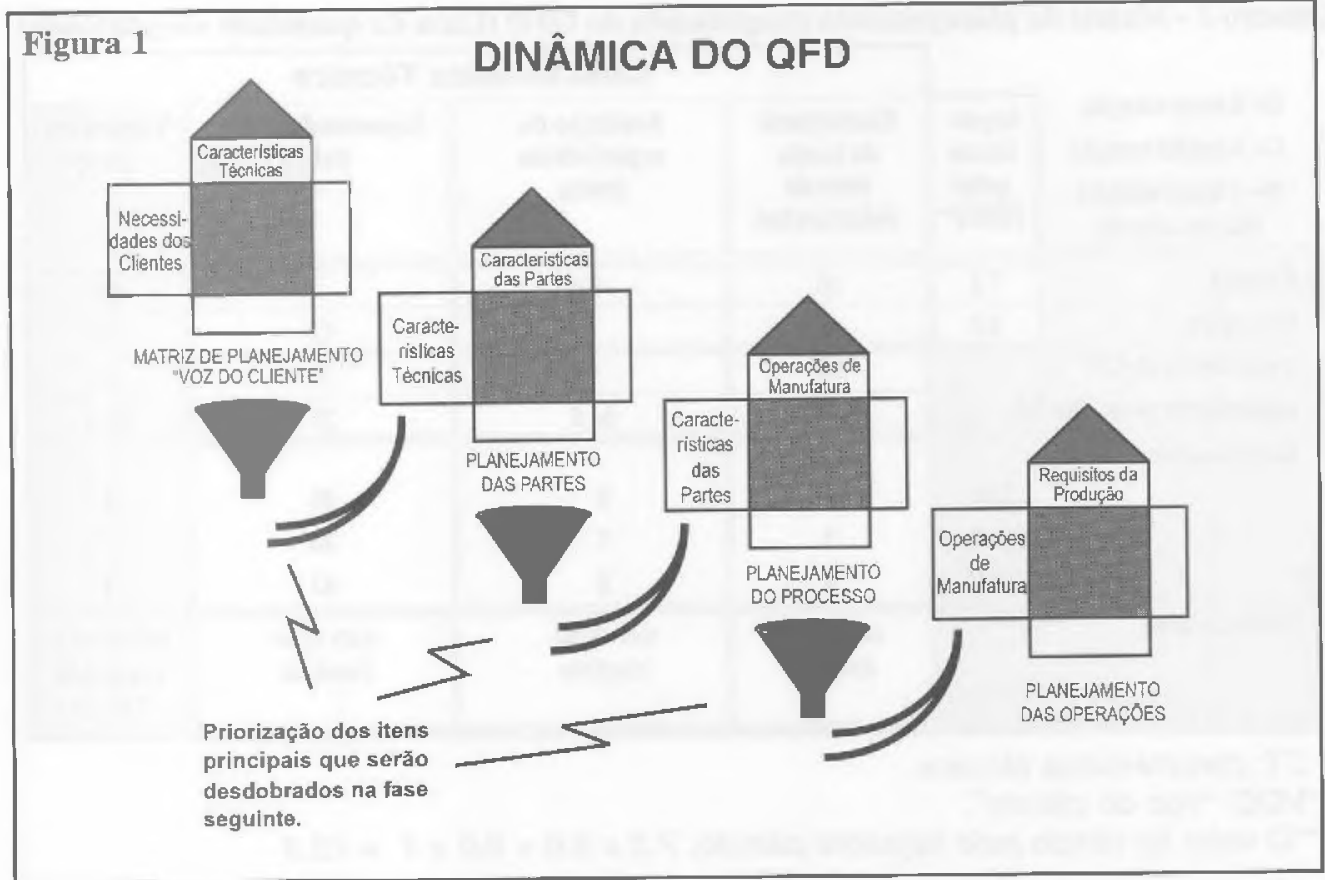

\section{Um exemplo}

Mediante um exemplo simplificado, imaginemos que desejamos melhorar a qualidade de nossa massa de pizza, e para tanto, por meio de vários critérios ${ }^{15}$ entre diversos itens da "voz do cliente", definimos dois como os mais importantes: "o pedaço não deve dobrar ao servir" e "é macia", como mostra o quadro 1 .
Uma vez feito o planejamento de nosso produto, é necessário ativá-lo por todo o processo de desenvolvimento de produtos da empresa de pizza. Uma proposta de desdobramento das matrizes do QFD é apresentada de forma bem simplificada na figura 2. Definido o foco de ação da equipe de desenvolvimento para a característica técnica que vai trazer mais impac-

\begin{tabular}{|c|c|c|c|c|}
\hline \multirow[t]{2}{*}{ Quadro 1} & \multicolumn{4}{|c|}{ Critérios } \\
\hline & $\begin{array}{l}\text { Importância } \\
\text { para o cliente } \\
\text { 1- não faço } \\
\text { questầo } \\
2 \text { - pagaria mais } \\
\text { caro para ter }\end{array}$ & $\begin{array}{l}\text { Percepçāo frente ao } \\
\text { melhor concorrente } \\
\text { (percepçăo do cliente) } \\
1.5 \text { - muito abaixo } \\
1.2 \text { - abaixo } \\
1.0 \text { - igual ou melhor }\end{array}$ & $\begin{array}{c}\text { Importância para } \\
\text { esforço promocional } \\
1.5 \text { - promover } \\
1.2 \text { - mencionar } \\
1.0 \text { - sem ação }\end{array}$ & $\begin{array}{l}\text { Importância } \\
\text { geral }\end{array}$ \\
\hline Não dobrar ao servir & 4 & 1.5 & 1.5 & 9.0 \\
\hline Fácil de manusear & 3 & 1.0 & 1.2 & 3.6 \\
\hline Emacia & 5 & 1.2 & 1.2 & 7.2 \\
\hline Borda deve ser dourada para marrom & 2 & 1.0 & 1.0 & 2.0 \\
\hline
\end{tabular}

Uma vez identificadas a "voz do cliente" e a importância de cada item, devemos definir características técnicas que permitam controlar esses itens de forma objetiva e quantificável. $\mathrm{O}$ quadro 2 mostra as principais características técnicas para os dois itens escolhidos.

De posse dessas informações, podemos montar a primeira matriz do QFD e iniciar o processo de desdobramento a partir do processo da priorização. A matriz de planejamento simplificada ${ }^{16}$ é mostrada no quadro 3.

\section{Quadro 2}

\begin{tabular}{|c|c|c|}
\hline $\begin{array}{l}\text { "Voz do } \\
\text { cliente" }\end{array}$ & $\begin{array}{l}\text { Impor- } \\
\text { tância }\end{array}$ & $\begin{array}{c}\text { Característica } \\
\text { técnica }\end{array}$ \\
\hline \multirow[t]{2}{*}{ Nāo dobra } & \multirow[t]{2}{*}{9.0} & $\begin{array}{l}\text { Impermeabilidade (mim } \rightarrow \\
\text { tempo de resistência a } 80 \mathrm{~g} \text { de } \\
\text { molho de tomate }\end{array}$ \\
\hline & & Espessura (mm) \\
\hline & - & 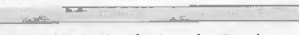 \\
\hline \multirow[t]{2}{*}{ É macia } & \multirow[t]{2}{*}{7.2} & $\begin{array}{l}\text { Elasticidade da borda } 5 \mathrm{mim} \text {. } \\
\text { após sair do forno (mm de } \\
\text { deformação a pressão I PSI) }\end{array}$ \\
\hline & & $\begin{array}{l}\text { Avaliaçāo de especialistas } \\
\text { (nota } 1-10 \rightarrow \text { média) }\end{array}$ \\
\hline
\end{tabular}

15. Na pratica do QFD nas empresas, vários aspectos sāo analisados ponderados em conjunto para se determinar a importẫncia significativa de cada item para a hierarquizaçảo da "voz do cliente". como, por exemplo, importăncia por segmento de mercado, avaliação frente aos concorrentes. histórico de reclamaçōes, perspectiva de alavancagem das vendas, perspectivas estrategicas etc. É importante salientar que os aspectos a serem utilizados devem ser determinados a partir de uma avaliação do produto a do mercado.

16. As matrizes de planejamenlo mais sotisticadas contam com um "telhado" em que se correlacionam as intluências entre as caraclerísticas técnicas e em que se verifica se cada influêncla determinada positiva ou negativa (se a melhoria de uma caracterísitca técrica implica melhoria ou piora da outra). 
Quadro 3 - Matriz de planejamento simplificada do QFD (Casa da qualidade simplificada)

\begin{tabular}{|c|c|c|c|c|c|}
\hline \multirow[b]{2}{*}{$\begin{array}{l}\text { ○- } 9 \text { forte relação } \\
0.3 \text { média relação } \\
.1 \text { fraca relação } \\
\text { Voz do cliente }\end{array}$} & \multirow[b]{2}{*}{$\begin{array}{c}\text { Impor- } \\
\text { tância } \\
\text { geral } \\
(\text { VOC) })^{\star *}\end{array}$} & \multicolumn{4}{|c|}{ Característica Técnica } \\
\hline & & $\begin{array}{c}\text { Elasticidade } \\
\text { da borda } \\
\text { (mm de } \\
\text { deformaçāo) }\end{array}$ & $\begin{array}{c}\text { Avaliaçāo de } \\
\text { especialistas } \\
\text { (nota) }\end{array}$ & $\begin{array}{l}\text { Impermeabilidade } \\
\text { (min) }\end{array}$ & $\begin{array}{l}\text { Espessura } \\
\text { (mm) }\end{array}$ \\
\hline E macia & 7.2 & (c) & ○ & & 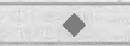 \\
\hline Nāo dobra & 9.0 & $\bullet$ & & 0 & ○ \\
\hline \multicolumn{2}{|l|}{ Importância da $\mathrm{CT}^{*}$} & 10 & 9 & 3 & 10 \\
\hline \multicolumn{2}{|c|}{ Importância geral das CT } & $73.8^{* * * *}$ & 64.8 & 27 & 88.1 \\
\hline \multicolumn{2}{|l|}{ Benchmarking: } & & & & \\
\hline & Nós & 3 & 8 & 40 & 2 \\
\hline \multicolumn{2}{|c|}{ Concorrente $\mathrm{A}$} & 3 & 7 & 36 & 2 \\
\hline \multicolumn{2}{|c|}{ Concorrente B } & 4 & 8 & 43 & 4 \\
\hline \multicolumn{2}{|l|}{ Plano de ação } & $\begin{array}{l}\text { sem açāo } \\
\text { imediata }\end{array}$ & $\begin{array}{l}\text { sem ação } \\
\text { imediata }\end{array}$ & $\begin{array}{l}\text { sem açāo } \\
\text { imediata }\end{array}$ & $\begin{array}{c}\text { aumentar a } \\
\text { espessura } \\
1.5 \mathrm{~mm}\end{array}$ \\
\hline
\end{tabular}

${ }^{*}$ CT: característica técnica.

* "VOC: "voz do cliente".

${ }^{* * *}$ O valor foi obtido pelo seguinte cálculo: $7.2 \times 9.0+9.0 \times 1=73.8$

to na satisfação do cliente e nas vendas, através da matriz de planejamento (no nosso exemplo, a espessura da massa) podemos iniciar o processo de desdobramento do QFD.

A segunda matriz, "planejamento das partes", tem como objetivo determinar as características técnicas das matérias-primas utilizadas (farinha, fermento etc.) que apresentem a melhor adequação à meta de atingirmos uma nova espessura para a massa.

A terceira matriz, "planejamento do processo", procura determinar as características de manipulação das matérias-primas de forma a garantir que com a quantidade de fermento determinada ( $30 \mathrm{~g}$ ) seja possível obter a espessura desejada por exemplo, o tempo de sova, tempo de descanso etc.

A quarta matriz irá abordar as questões referentes às atividades críticas ao sucesso dos objetivos determinados na planilha de planejamento. No nosso exemplo, o treinamento do masseiro na forma de sovar adequada.

$\mathrm{O}$ aspecto importante que este exemplo deve deixar claro é que a "voz do cliente" é respeitada em todas as fases, até a obtenção do novo produto. Um resultado secundário do QFD é que ele fornece, já no projeto, todos os parâmetros importantes para o controle da qualidade do futuro produto referentes à satisfação do cliente. Por isso, o QFD é reconhecido como uma das melhores ferramentas para a garantia da qualidade no projeto, tão desejada pelas empresas.

\section{IMPACTO DO QFD NO DESENVOLVIMENTO DE PRODUTOS}

Considerando o conceito de qualidade em sua forma mais ampla — a satisfação do cliente — verificamos que o QFD também é uma forma de garantir um projeto de qualidade enquanto o produto ainda está nos estágios iniciais de seu projeto. ${ }^{17}$ É pressuposto do QFD entender a qualidade como um fazer certo desde a primeira vez, e isto significa focar qualidade no projeto, pois a qualidade na produção será em grande parte consequiência do projeto. A qualidade que depende diretamente das condições de produção representa a menor parte dos problemas de qualidade que as empresas enfrentam, já que a maior parte reside nas falhas de projeto.

Ao identificar que o processo de desenvolvimento de produtos apresenta, em sua forma tradicional, poucas chances de atender seu principal objetivo ${ }^{18}$ que é a efetiva satisfação das necessidades e desejos dos clientes, Merli ${ }^{19}$ aponta as principais causas que levam as empresas a falhar, expostas no quadro 4 . Cabe salientar que o método QFD atende a cada um dos pontos citados.

O QFD também pode ser considerado um efetivo instrumento para implantaçāo de benchmarking ${ }^{20}$ para o produto ou serviço, pois relaciona as comparações do produto com os concorrentes mediante avaliações técnicas (geralmente, testes em laboratórios e processos de 
Figura 2

\section{O DESDOBRAMENTO DO QFD}

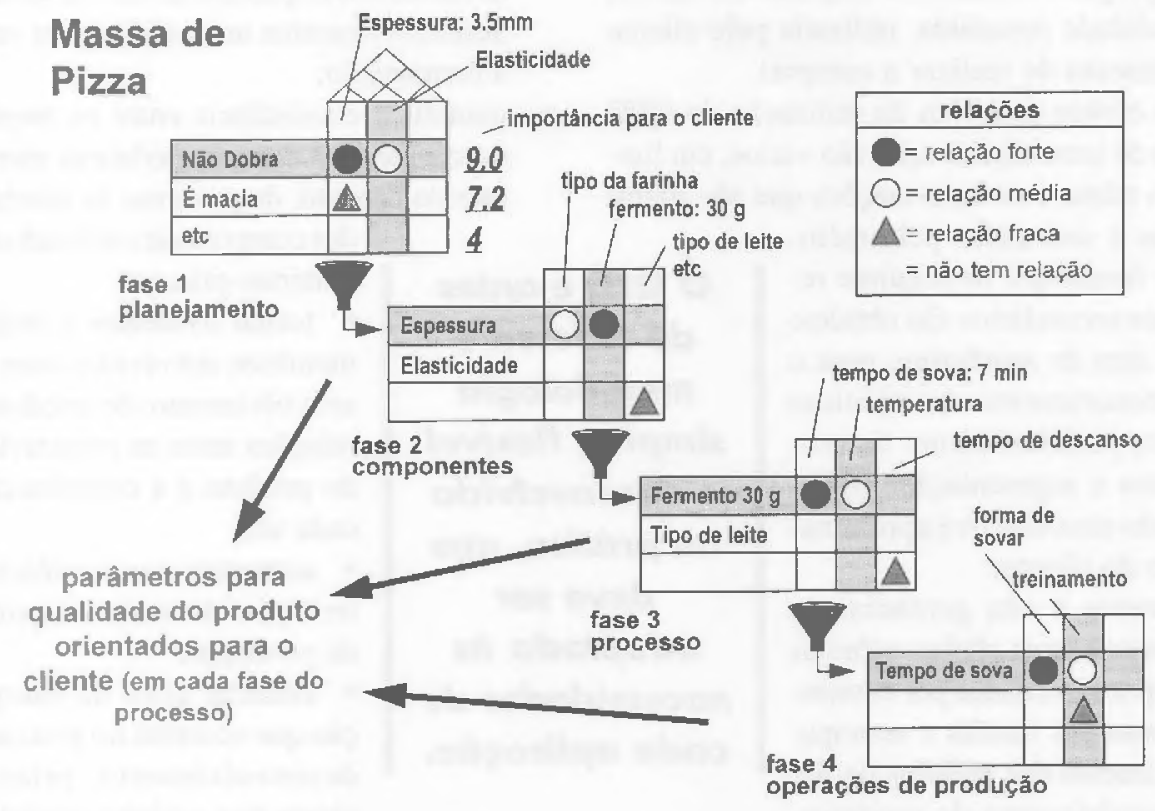

* O layout de apresentação desta figura se baseou em trabalho, não publicado, de José Amaro dos Santos, doutorando da EAESP - FGV.

Quadro 4

\begin{tabular}{|c|c|}
\hline \multicolumn{2}{|c|}{ RAZÕES PARA O FRACASSO NO DESENVOLVIMENTO DE PRODUTOS } \\
\hline PRINCIPAIS CAUSAS & SEUS RESULTADOS \\
\hline $\begin{array}{l}\text { - falta de compreensão das necessidades dos } \\
\text { clientes, os quais geralmente expressam seus } \\
\text { desejos de forma indefinida e fragmentada, } \\
\text { e por isso suas expectativas são normalmente } \\
\text { vagas e não formuladas; }\end{array}$ & $\begin{array}{l}\text { - compreensão insuficiente das qualidades } \\
\text { requeridas pelos clientes; }\end{array}$ \\
\hline $\begin{array}{l}\text { - dificuldade em transformar necessidades } \\
\text { expostas verbalmente em expressöes } \\
\text { numéricas, necessárias para especificar um } \\
\text { produto; }\end{array}$ & $\begin{array}{l}\text { - ênfase na qualidade de características } \\
\text { mensuräveis erroneamente consideradas } \\
\text { importantes; }\end{array}$ \\
\hline $\begin{array}{l}\text { - transferência incompleta de informações } \\
\text { do inicio do processo de desenvolvimento } \\
\text { (marketing etc.) ao seu fim (produção etc.); }\end{array}$ & $\begin{array}{l}\text { - decisões importantes sobre produtos são } \\
\text { delegadas a técnicos com pouca visão do } \\
\text { mercado e, às vezes, do processo } \\
\text { (principalmente decisões relacionadas } \\
\text { à produção); }\end{array}$ \\
\hline $\begin{array}{l}\text { - dificuldade em determinar e quantificar as } \\
\text { características prioritárias a serem } \\
\text { desenvolvidas, pontos críticos a serem } \\
\text { solucionados e em comparar os produtos } \\
\text { com os concorrentes. }\end{array}$ & $\begin{array}{l}\text { - pouca compreensão da importância crítica } \\
\text { dos aspectos relacionados com a engenharia } \\
\text { de produçāo. }\end{array}$ \\
\hline
\end{tabular}


engenbaria reversa de itens que definem a qualidade efetiva e técnica do produto) com a avaliação competitiva (as comparações realizadas pelos próprios clientes da empresa em termos da qualidade percebida, utilizada pelo cliente no momento de realizar a compra).

Os efeitos positivos da utilização do QFD dentro de uma organização são vários, em função do número de informaçōes que são manipuladas e ordenadas pelo método, de forma que os seguinte resultados secundários são obtidos:

- na área de marketing, gera o aprimoramento das técnicas para posicionamento de produtos e segmentação, garantindo uma objetiva aproximação do cliente;

- permite à alta gerência um controle mais efetivo sobre as responsabilidades por cumprimento das tarefas e acompanhamento dos projetos de desenvolvimento de produtos, por vincular as metas estabelecidas no planejamento estratégico da empresa ao programa de desenvolvimento.

O QFD tem se mostrado particularmente eficiente às empresas que adotam conceitos de desenvolvimento simultâneo, pois, juntamente com redes de CAD, assume o papel de linhaguia (definida a partir da "voz do cliente") para todos as áreas envolvidas no processo de desen- volvimento, conforme mostra a figura 3.

Resumindo, o QFD toma possível à empresa:

- definir especificações de produto para atender tanto aos requisitos do cliente como aos desenvolvimentos necessários para superar a competição;

- garantir a consistência entre os requisitos do cliente e os das características mensuráveis do produto, do processo de montagem, dos componentes utilizados e das matérias-primas;

- tornar evidentes a todos os membros envolvidos com o desenvolvimento de produtos as relaçōes entre as características do produto e a contribuição de cada um;

- aumentar a consistência entre o planejamento e o processo de produção;

- eliminar erros de interpretaçāo que ocorrem no processo de desenvolvimento, principalmente nos estágios iniciais.

\section{COMENTÁRIOS PARA A APLICAÇÃO DO QFD}

O método QFD pode ser descrito em uma sequência lógica e temporal de sete fases distintas no seu desenvolvimento: ${ }^{21}$

1. Pcrccpção completa e correta das necessidades e solicitaçōes dos clientes, aqui entendi-

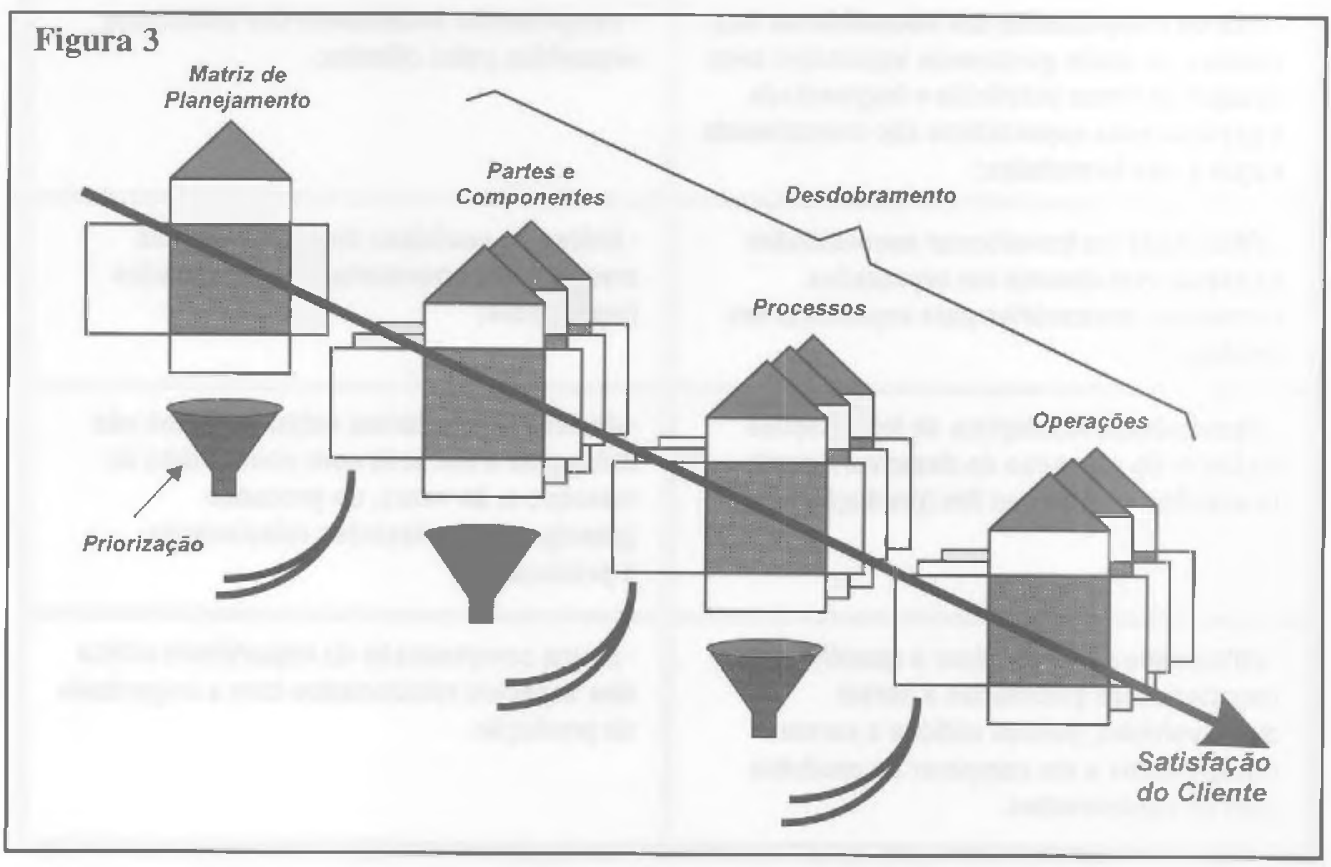


do principalmente o usuário final, mas incluindo todos os que manipulam o produto, tanto internamente à empresa como externamente.

2. Determinação pelo próprio cliente da importância de cada solicitação feita, da avaliação de cada uma frente aos principais concorrentes. $^{22}$

3. Tradução clara, competente e completa das solicitações dos clientes em características técnicas do produto, bem como determinação das medições para cada uma frente à concorrência (benchmarking).

4. Planejamento, design e determinação de especificações para cada detalhe individual de cada característica do produto.

5. Tradução das especificações de cada detalhe do produto em especificações do processo de produção.

6. Definição das condições operacionais específicas e dos procedimentos que devem ser consistentemente utilizados na produção.

7. Acompanhamento da produção inicial e definição das características da performance do produto e das instruções para o seu uso.

\section{RECOMENDAÇÕES AOS NOVOS USUÁRIOS DO MÉTODO QFD}

Embora a aplicação do método não seja complicada ou difícil, requer sistematização e planejamento. Algumas tabelas utilizadas pelo sistema chegam a ser medidas em metros, considerando mais de uma centena solicitações dos clientes e igual tamanho de especificações técnicas (o que deve ser evitado). Por isso, algumas recomendações devem ser feitas àqueles que desejam aplicar o QFD:

- Utilizar um software específico, pois as matrizes do QFD funcionam de duas formas: como um área de trabalho da equipe do projeto para a discussão e desenvolvimento de soluções e como um arquivo de fácil acesso às informações e dados que geraram as conclusões apresentadas na matrizes.

- Manter as matrizes restritas ao limite máximo de 30 a 50 itens para a "voz do clien- te", mediante a aplicação de uma matriz de pré-planejamento.

- Os conceitos e técnicas desenvolvidos para o QFD refletem um esforço em tornar claras as relações interfuncionais na organização para garantir a satisfação do cliente, o que não é facilmente perceptível, pois, mesmo que um problema específico seja óbvio, seus relacionamentos com outros atributos percebidos pelos clientes podem permanecer obscuros. Por isso, o desenvolvimento de projetos com o QFD deve ser feito em equipes.

A grande vantagem do $Q F D$ é que sua implantação não é complexa, uma vez que é delimitada dentro da organização (restrita ao projeto que está sendo aplicado) e de sua objetividade (todos os projetos de QFD devem ter um objetivo claro e mensurável, indicadores de progresso e prazo de duração). Outro fator importante é que o envolvimento das diversas áreas da empresa é feito à medida que for necessário ao projeto, portanto sem a geração de ansiedades e criação de expectativas desnecessárias.

Apesar dessa simplicidade da implementação do QFD, requer-se atenção e envolvimento da alta direção, na figura de um executivo sênior como patrocinador e avalista dos recursos necessários para o projeto. Também a existência de uma cultura propícia ao trabalho em equipe, a preocupação com a qualidade e visão de processos entre os membros da empresa facilitam a implantação do QFD.

Por outro lado, o QFD pode funcionar (e na prática o faz) como um elemento de transformação da organização. Por ser estruturado e orientado pela "voz do cliente", o QFD torna-se uma das melhores ferramentas para o trabalho em equipe, não abrindo espaço para disputas de poder entre os membros das áreas participantes do projeto ou, no outro extremo, para divagações que levam à perda de fqco nos objetivos iniciais. Afinal, como colocam Hauser e Clausing: $:^{23}$ "O principal benefício do $Q F D$ é fazer qualidade dentro da empresa. $O$ que implica pessoas pensando na direção certa e pensando juntas. Para as maiorias das empresas isto significa, por si só, uma revolução silenciosa."
22. Nesta fase, a equipe de QFD pode considerar tambèm: (i) a inserçāo da avaliação do marketing para cada item (considerando a possibilidade de obter mais vendas mediante um esforço promocional a partir de um dado item conceito Unique Selling Point - USP); (ii) as reclamaçōes registradas pela empresa para cada item solicitado pelo cliente. desta forma integrando a área de pósvenda da empresa; (iii) outros pontos que cada aplicação específica do OFD vier solicitar. Novamente, cabe lembrar que 0 OFD é antes de tudo uma metodologia flexivel desenvolvida na prática, que deve ser adaptada às necessidades de cada aplicação.

23. HAUSER, J. R., CLAUSING, D., p. 73. 